\title{
Post Traumatic Stress Disorder in Schooled Adolescents in Detention
}

\author{
Khalid Astitene ${ }^{1}$, Amina Barkat ${ }^{1,2}$ \\ ${ }^{1}$ Health and Nutrition Research Team of the Mother and Child Couple, Faculty of Medicine and Pharmacy of Rabat, \\ Mohammed V University of Rabat, Rabat, Morocco \\ ${ }^{2}$ Department of Neonatal Medicine and Resuscitation, Ibn Sina Children's Hospital, Rabat, Morocco \\ Email: ast_khialid@yahoo.fr
}

How to cite this paper: Astitene, K. and Barkat, A. (2018) Post Traumatic Stress Disorder in Schooled Adolescents in Detention. Open Access Library Journal, 5: e4929.

https://doi.org/10.4236/oalib.1104929

Received: September 19, 2018

Accepted: October 21, 2018

Published: October 24, 2018

Copyright $\odot 2018$ by authors and Open Access Library Inc.

This work is licensed under the Creative Commons Attribution International License (CC BY 4.0).

http://creativecommons.org/licenses/by/4.0/

\begin{abstract}
Objective: The detention have a negative impact on the psychological well-being of adolescents in detention; the purpose of our study is to assess the post-traumatic stress disorder PTSD in a incarcerated adolescents in school at the level of the centre of reform and discipline of the prefecture of Sale in Morocco, to evaluate comorbid disorders and thus to study the effect of PTSD on their social and school life. Method and measures: Regarding to 52 adolescents, incarcerated male in school who have complemented the objectives of the study, their age varies between 13 and 17 years old and they supplemented by themselves successively questionnaires concerning sociodemographic data, a list of life events score, the CPTS-RI (Children Post Traumatic Stress Reaction Index) to assess the symptoms of PTSD, the STAIY (State Trait anxiety Inventory) and CDI (Children Depression Inventory). Results: A high proportion of post-traumatic stress disorder was found among students with $78.85 \%$ but with different levels (23.08\% PTSD low, 28.85\% PTSD moderate and 26.92\% PTSD severe). $84.62 \%$ of students are anxious and $82.7 \%$ of students experience depression. In the event the main traumatic condition that caused the post-traumatic stress disorder was detention with $44.2 \%$ followed by a road accident with $15.4 \%$. PTSD, anxiety and depression have a negative effect on students' school life; therefore, $90.4 \%$ of students have poor grades. Conclusion: Given this specific category of students who are in detention and who are in deficit serious school, we have this high rate of post-traumatic stress disorder. There are the practical implications for the support and care for these adolescents.
\end{abstract}

\section{Subject Areas}

Psychology 


\section{Keywords}

Adolescent, Traumatic Event, CPTS-RI, Post-Traumatic Stress Disorder, Detention

\section{Introduction}

When it is an event that causes or may cause trauma, this is called a traumatic or potentially traumatic event. Traumatic events often involve many people: victims, direct witnesses, indirect witnesses, relatives, and institutions concerned. A similar event experienced by different people may have very different traumatic effects from person to person.

To have a traumatic effect, the event must represent a threat (real, potential or imagined) for the physical and psychological integrity of the person, in front of which the victim feels unable to react, to arise from sudden and unforeseen manner, accompanied by feelings of helplessness, terror, distress, terror, loneliness, and abandonment, etc. The range of traumatic events is wide and we cite physical violence, sexual violence, exposure to violent scenes, war, the death of a loved one, a natural disaster, an accident, repeated or ongoing situations of "moderate" violence. The traumatic event is particularly expressed in everyday life by a post-traumatic stress disorder (PTSD), which is one of the most common mental disorders, serious and debilitating that may appear following trauma.

The clinical signs of PTSD in adolescents generally resemble the post-traumatic responses of adults [1]. However, adolescents can show specificities with extreme reactions such as becoming more impulsive or abusing substances [2]. Adolescents may also verbally exaggerate dichotomous, somatization and blame others for what happened [3].

This study is aimed to identify the prevalence of the post-traumatic stress disorder (PTSD) in a population specific and particular composed by adolescents in school (in view of the major interest of the continuity of the education of adolescents in school for their well-being) in incarceration for schoolboys and students at the centre of reform and discipline of the prefecture of Salé. To my knowledge, there is no work in the Morocco or little work at the global level which is related to the subject of our study and there is little published studies which have investigated possible associations between the impact of detention and teenagers attend school on their psychological well-being and especially on the appearance of certain psychological disorders as the disorder of the post-traumatic stress disorder that has been studied in our work and the relationship of this social disorder with the life and the schooling of these adolescents.

As well as evaluation of symptomatology in connection with PTSD and in our work, we limit ourselves to two co-morbid disorders which are anxiety and de- 
pression and what are the observed disorders after a post-traumatic stress disorder.

\section{Methods and Materials}

\subsection{Study Population}

It is a cross-sectional survey, our study was carried out at the level of the prison called also Center of reform and discipline of the city of Salé, located to the West of the Morocco, this Center was so called because it has as miners offenders of male with an age less than 20 years and it welcomes that the miners of the territorial region of Rabat-Salé. This Center includes a school for in prison them who want to receive education. Our study seeks adolescents with an age less than 18 years saw our investigation standards, so that the number of incarcerated school adolescents is 68 students, 14 of them have refused to participate in the study.

Students who participated in this work were 54 adolescents in detention and their age is between 13 and 17 years, who continue their study according to two grade levels, 40 at the college and in high school 12 (without taking into account the terminal of high school because their age is more than 17 years), but 2 teenagers who have not completed the questionnaires, this is how they had treated data from 52 teenagers. Figure 1 shows the final sample of the students who have completed the entire procedure of inquiry. The crimes of these teenagers are varied: armed, homicide, robbery, rape, theft and setting up a criminal gang.

The participation rate was therefore $79.41 \%$. The percentage of students who were at least exposed to a traumatic event in their lifetime is $96.3 \%$.

\subsection{The Inclusion and Exclusion Criteria}

The inclusion criteria:

- Have lived or witnessed a potentially traumatic event.

- To be currently educated.

- Being present at the center of reform and discipline during the course of the study.

- Do not go beyond the age of 17 years.

- Have given informed consent.

The exclusion criteria:

- Do not be currently in school.

- Inmates who will leave the center of reform and discipline during the course of the study.

- Exceed the age of 17 years.

- Refuse to participate.

- Do not have a mental disability.

\subsection{Judgment Criteria}

The primary judgment criterion was the self-assessment of students with the Children Post Traumatic Stress Reaction Index (CPTS-RI) which was conducted 


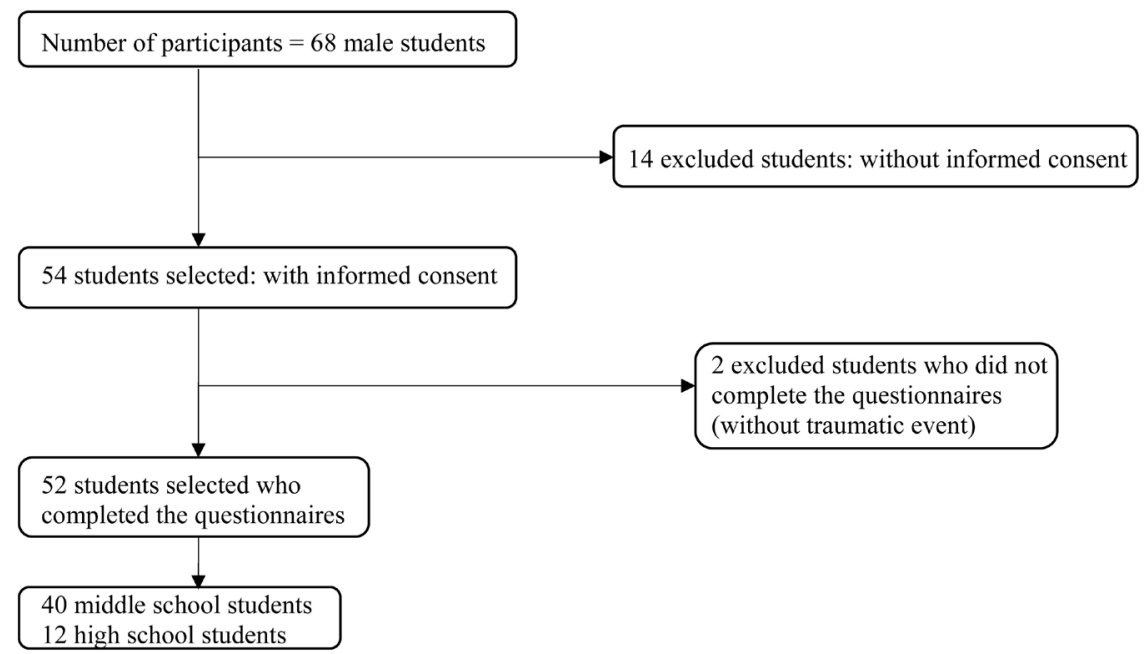

Figure 1. Participant presentation diagram.

in a direct meeting with students to assess the state of post traumatic stress, this scale has 20 items with 5 levels of scores, a score above 12 suggests the presence of a post-traumatic stress disorder with 4 categories of severity depending on the score obtained.

The secondary objectives were to assess the presence of symptoms of comorbid anxiety and depressive disorders, respectively through questionnaires State Treatment Inventory Anxiety Form Y (STAIY) and Children Depression Inventory (CDI).

\subsection{Procedure}

A first meeting was established with the incarcerated teenagers to explain the purpose and interest of the study, and then they received a newsletter explaining the purpose of the study and the informed consents that must be signed by their parents or guardians. In the second meeting and after receiving the informed consents signed by the adolescents who agreed to participate in the study, the data was collected using two questionnaires that were completed only by the adolescents (A data questionnaire sociodemographic and a checklist of life events). In the third meeting, the rest of the data were collected using three questionnaires which were completed by themselves (CPTS-RI, STAIY and the CDI successively). All the data was totally anonymous and I was there for all the meetings to answer any questions. Namely that these teenagers were divided into two groups because of their number and for communication between the researcher and them is easier.

\subsection{Materials Used}

Measuring instruments self-administered to students collected data on the socio-demographic characteristics of the adolescent and his family and the symptoms of various disorders in the student. These instruments were administered according to the following steps: 
- A questionnaire of socio-demographic data.

- Life Events Checklist is a list of challenging or stressful situations that students may have to experience and presents 17 questions to evaluate PTSA Criterion A as described by the DSM-IV Diagnosis and Statistical Manual for Mental Disorders (Diagnostic and Statistical Manual of Mental Disorders Version IV) [4]. For subjects who have never been confronted with a traumatic event defined by criteria A1 and A2 of the DSM-IV the investigations stopped, while the subjects having been confronted with a traumatic event the investigations continued.

- The CPTS-RI (Children's Post Traumatic Stress Reaction Index) to assess symptoms of PTSD after exposure to various traumatic events [5] and can be used as a self-administered scale in adolescents.

The CPTS-RI is one of the best studied tools and one of the most used in the world to detect PTSD and to quantify the intensity of the symptomatology given the good quality of its psychometric properties. 20-item scale for children from 6 to 16 years, each item on the scale is rated in 5 levels ( 0 never, 1 almost never, 2 sometimes, 3 often, 4 most often). The overall score varies between 0 and 80 . The duration is 15 to 20 minutes. The CPTS-RI is a flexible tool that has been adapted to children or adolescents from different cultures, facing various traumatic experiences. It has been translated into several languages (English, Arabic, Croatian, Norwegian, Vietnamese and French).

The gradation into 4 categories according to the score is as follows: a score between 12 and 24 indicates a low level of PTSD, between 25 and 39 a moderate level, between 40 and 59 a severe level and a score of over 60 a very severe level.

CPTS-RI items corresponding to diagnostic criteria B (Symptoms of Reviviscence), C (Symptoms of avoidance and dullness) and D (Symptoms of over-activation) of the DSM III-R (American Psychiatric Association, 1987). However, the diagnostic criteria for PTSD are not very different between the DSM-III-R and the DSM-IV, they are only slightly different in the approach of certain symptoms and the DSM-III, DSM-III-R, DSM-IV criteria have been shown to have stable diagnostic validity rates.

- A self-assessment questionnaire that assesses anxiety levels STAIY (State Trait Inventory Anxiety Form Y Spielberger, 1983, French version of Brochon-Schweitzer and Paulhan, 1993) [6], anxiety represents feelings of apprehension, tension, nervousness and anxiety that the subject feels. The time is not limited, but on average students take 10 minutes to complete the questionnaire. This scale includes 20 items, each answer to a questionnaire item corresponds to a score from 1 to 4 ( 1 indicating the lowest degree of anxiety, 4 the highest degree). This scale has lines indicated by I and lines indicated by $\mathrm{O}$. For the lines indicated by I, the answer "no" is rated 4 , rather no $=3$, rather yes $=2$ and yes $=1$. For the lines indicated by 0 , the "no" is rated 1 , rather no $=2$, rather yes $=3$, yes $=4$. The total score thus varies from 20 to 80. The grades can be divided into five levels: higher than 65 (very high), 56 
to 65 (high), 46 to 55 (medium), 36 to 45 (low), lower at 35 (very weak).

- A self-evaluation questionnaire that assesses the level of CDI depression (Children Depression Inventory) [5], this scale specifically evaluates the intensity of the symptomatology depressed (feelings of sadness, ability to take pleasure, suicidal ideation, feeling tired, academic efficiency, interpersonal relationships).

Depression is a disorder that is characterized by a profound change in the mood state in the sense of sadness, moral suffering and accompanied by many somatic symptoms.

The IDC targets children and adolescents aged 7 to 17 years and include 27 items. Each item contains three sentences describing, by increasing intensity, a depressive manifestation. The student must choose the sentence that best fits his condition in the last fifteen days. The duration of handover is 15 to 20 minutes. Each item is rated from 0 (absent or normal) to 2 (severe). A total score is calculated by the sum of all items, it ranges from 0 to 54 .

\subsection{Definitions of Terms}

Trauma: This is an important emotional shock, usually related to a situation where a person or group of people has felt their life in danger and jeopardizes their psychic balance. These situations exceed the management capabilities of the majority of individuals.

Stress: It is a reflex, neurobiological, physiological and psychological reaction of alarm, mobilization and defense, of the individual in the face of an aggression, a threat or an unexpected situation. Next to a trauma, the individual can react in different ways, adapted or not.

Traumatic event: According to the DSM-IV-TR: “The subject has lived, witnessed or been confronted with an event or events during which individuals may have died or be very seriously injured or have been threatened with death or serious injury or where their physical integrity or that of others may have been threatened. The subject's reaction to the event resulted in intense fear, feeling impotence or horror".

Post-Traumatic Stress Disorder (PTSD): Whether in ICD-X or DSM-IV-R, PTSD is a combination of symptoms that can be used to diagnose it. These symptoms are consecutive to exposure to a traumatic event. They may be revealed or prolonged in time, beyond the withdrawal of the subject from the traumatic situation.

Anxiety: It is a biological mechanism that protects us from stressful and dangerous situations. The symptoms are an irrational and excessive fear, feeling of apprehension and tension, difficulty in managing the daily tasks, anxious thoughts, or excessive physical responses to the context.

Depression: This is a complex mood disorder caused by a variety of factors including genetic predisposition, personality, stress, and brain chemistry. The main symptom is a state of sadness or despair that is usually present and affects 
the person's performance at work, school or social relations.

\subsection{Statistical Analysis}

The data collected were statistically processed using SPSS (Statistical Package for the Social Sciences) software version 13; this version was obtained at the laboratory of biostatistics and Clinical Research and Epidemiology (LBRCE) of the Faculty of Medicine and Pharmacy in Rabat-Morocco. The data were processed for a descriptive statistical analysis, these data were presented in the form of and percentage for each variable studied. Continuous or quantitative variables were also expressed as mean and standard deviation. The comparison of the quantitative variables was performed using the $\mathrm{T}$ test of Student. The comparison of qualitative or categorical variables was performed by a chi-square test. A correlation was made for a comparison between the continuous variables using the Pearson correlation. The level of statistical significance was considered when $\mathrm{p}<0.05$.

\subsection{Ethical Considerations}

The research project began after receiving a research authorization from the Ministry of National Education. The work was first introduced by the information necessary for the informed consent of the participants. Students were informed of the research objectives and the confidentiality of the answers, followed by letter information explaining the purpose of the study and prior informed consent were sent to the parents or guardians of the 68 students. After their agreement on the study, the prior consent forms were signed by 54 students.

\section{Results}

\subsection{Traumatic Characteristics and Events of the Sample}

1) Sociodemographic data:

All the participants belonged to the region of Rabat-Salé because the center of reform and discipline which is at the level of the prefecture of Salé must welcome only the people of this region.

The 52 students completed a questionnaire on their social, family, school and consumption status of psychoactive substances (tobacco, alcohol and illicit drugs). Table 1 shows the different sociodemographic data of students.

For the high school, it was not possible to introduce students of terminal level (baccalaureate) who are of number 6 pupils because they exceed 17 years.

The average age of students was 15.81 (standard deviation $=1.314$ ), the average number of students' brothers was 3.38 (standard deviation $=3.107$ ). Parents' income was low with an average of 2 out of 6 on the scale which implies that it is around 2000 dirhams and 4000 dirhams per month (standard deviation $=1.237$ ). With regard to psychoactive products, smoking frequency per week seemed too high with an average of 6.17 (standard deviation $=2.055$ ), alcohol frequency per week was low with an average of 0.87 standard deviation $=1.572$ ) and the average frequency of illicit drug use per week (mostly Indian hemp also called hashish 
Table 1. Sociodemographic data.

\begin{tabular}{|c|c|c|}
\hline & Effective & Percentage (\%) \\
\hline \multicolumn{3}{|l|}{ Age } \\
\hline 13 & 3 & 5.8 \\
\hline 14 & 8 & 15.4 \\
\hline 15 & 8 & 15.4 \\
\hline 16 & 10 & 19.2 \\
\hline 17 & 23 & 44.2 \\
\hline \multicolumn{3}{|l|}{ City } \\
\hline Ain awda & 3 & 5.8 \\
\hline Khémisset & 5 & 9.6 \\
\hline Rabat & 15 & 28.8 \\
\hline Salé & 22 & 42.3 \\
\hline Témara & 7 & 13.4 \\
\hline \multicolumn{3}{|l|}{ Class } \\
\hline Middle school 1 & 12 & 23.1 \\
\hline Middle school 2 & 19 & 36.5 \\
\hline Middle school 3 & 9 & 17.3 \\
\hline High school 1 & 9 & 17.3 \\
\hline High school 2 & 3 & 5.8 \\
\hline \multicolumn{3}{|l|}{ Family situation } \\
\hline Married & 28 & 53.8 \\
\hline Divorced & 13 & 25.0 \\
\hline Death of one of the parents & 9 & 17.3 \\
\hline Host family & 2 & 3.8 \\
\hline \multicolumn{3}{|l|}{ Father's job } \\
\hline Trade & 15 & 28.8 \\
\hline Employee & 21 & 40.4 \\
\hline Public function & 6 & 11.5 \\
\hline Unemployed & 3 & 5.8 \\
\hline \multicolumn{3}{|l|}{ Mother's job } \\
\hline Trade & 1 & 1.9 \\
\hline Employee & 12 & 23.1 \\
\hline Unemployed & 38 & 73.1 \\
\hline \multicolumn{3}{|l|}{ Salary } \\
\hline Under $2000 \mathrm{dh}$ & 23 & 44.2 \\
\hline Between $2000-4000 \mathrm{dh}$ & 16 & 30.8 \\
\hline Between $4000-6000 \mathrm{dh}$ & 8 & 15.4 \\
\hline Between $6000-8000 \mathrm{dh}$ & 1 & 1.9 \\
\hline Between $8000-10,000 \mathrm{dh}$ & 3 & 5.8 \\
\hline More than $10,000 \mathrm{dh}$ & 1 & 1.9 \\
\hline \multicolumn{3}{|l|}{ Type of accommodation } \\
\hline House & 13 & 25.0 \\
\hline
\end{tabular}




\section{Continued}

\begin{tabular}{clcc}
\hline \multirow{2}{*}{ House rental } & 9 & 17.3 \\
& apartment & 9 & 17.3 \\
& Apartment rental & 14 & 26.9 \\
& Insalubrious housing & 7 & 13.5 \\
Tobacco & No & & \\
& Ylcohol & 4 & 7.7 \\
& No & 48 & 92.3 \\
& Yes & & \\
Illegal drugs & 34 & 65.4 \\
& No & 18 & 34.6 \\
& Yes & & 36.5 \\
\hline
\end{tabular}

or cannabis) was 3.17 ( $\mathrm{SD}=2.915$ ) so it's average consumption. The majority of students had a college level education (76.9\%). About half of the parents were in couples $(53.8 \%)$. Only $5.8 \%$ of fathers were unemployed, while $73.1 \%$ of mothers were housewives. $13.5 \%$ of families were found to have Insalubrious housing (lived in a garage, in a single room or in a slum).

2) Exposure to traumatic events:

The 52 students responded that they did not experience, during their lifetime, the following five types of traumatic events:

- Natural disaster.

- Fire or explosion.

- Exposure to a toxic substance.

- Participation in a fight or presence in a war zone.

- Intense human suffering.

There are students who have experienced one or more traumatic events in their lifetime. Table 2 illustrates the various traumatic events experienced by students during their life and the duration of the traumatic event.

For the traumatic event captivity, the case expressed for this event is detention (or incarceration) for all students. The most significant and stressful event was the detention with $44.2 \%$ of the students followed by the public road accident with $15.4 \%$, so we noticed that the students were influenced by their incarceration and the fact of being in prison. The average of the event date was 3.87 (standard deviation $=1.534)$ which implies that it is around 3 months and 6 months.

\subsection{Post Traumatic Stress Disorder and Comorbids Disorders}

After the student has chosen the most stressful and unpleasant traumatic event, completed the CPTS-RI questionnaire to assess the impact of this event and if it was likely to generate PTSD or not. Table 3 demonstrates the responses given by the student from the scale CPTS-RI. 
Table 2. Exposure to traumatic events and their duration.

\begin{tabular}{|c|c|c|}
\hline & Effective & Percentage (\%) \\
\hline \multicolumn{3}{|l|}{ 1) Event } \\
\hline - Accident of the public way & 8 & 15.4 \\
\hline $\begin{array}{l}\text { - Serious accident at school, at home or during leisure } \\
\text { activities }\end{array}$ & 1 & 1.9 \\
\hline - Physical aggression & 3 & 5.8 \\
\hline - Hold-up & 4 & 7.7 \\
\hline - Sexual assault & 1 & 1.9 \\
\hline - Another unwanted and unpleasant sexual experience & 1 & 1.9 \\
\hline - Captivity & 23 & 44.2 \\
\hline - Illness or life-threatening injury & 3 & 5.8 \\
\hline - Illness or life-threatening injury & 2 & 3.8 \\
\hline - Violent death (homicide, suicide, ...) & 3 & 5.8 \\
\hline - Sudden and unexpected death of a loved one & 2 & 3.8 \\
\hline $\begin{array}{l}\text { - Serious injury, damage or death caused by you to } \\
\text { someone }\end{array}$ & 1 & 1.9 \\
\hline \multicolumn{3}{|l|}{ 2) Date of event } \\
\hline Between one month and 3 months & 13 & 25.0 \\
\hline Between 3 months and 6 months & 10 & 19.2 \\
\hline Between 6 months and one year & 12 & 23.1 \\
\hline Between 1 year and 3 years & 8 & 15.4 \\
\hline Between 3 year and 5 years & 6 & 13.5 \\
\hline More than 5 years & 3 & 3.8 \\
\hline
\end{tabular}

Table 3. Responses to the Self-Assessment Scale Children Post Traumatic Stress-Reaction Index: CPTS-RI.

\begin{tabular}{|c|c|c|c|c|c|}
\hline CPTS-RI items & $\begin{array}{c}\text { Never } \\
(\%)\end{array}$ & $\begin{array}{c}\text { Almost } \\
\text { Never (\%) }\end{array}$ & $\begin{array}{c}\text { Sometimes } \\
(\%)\end{array}$ & Often (\%) & $\begin{array}{c}\text { Almost } \\
\text { every day } \\
(\%)\end{array}$ \\
\hline \multicolumn{6}{|l|}{ Exposure to a traumatic event } \\
\hline Traumatic event identification (A1) & 11.5 & 9.6 & 21.2 & 28.8 & 28.8 \\
\hline Regular fear (A2) & 9.6 & 21.2 & 34.6 & 26.9 & 7.7 \\
\hline \multicolumn{6}{|l|}{$\begin{array}{c}\text { Symptoms of reviviscences } \\
\text { of the event }\end{array}$} \\
\hline Repetitive images (B1) & 30.8 & 30.8 & 21.2 & 9.6 & 7.7 \\
\hline Repetitive thoughts (B1) & 28.8 & 30.8 & 7.7 & 11.5 & 21.2 \\
\hline Repetitive dreams (B2) & 34.6 & 40.4 & 11.5 & 9.6 & 3.8 \\
\hline Flashbacks (B3) & 53.8 & 13.5 & 11.5 & 11.5 & 9.6 \\
\hline Stunning memories (B4) & 32.7 & 34.6 & 13.5 & 9.6 & 9.6 \\
\hline Physiological reactivity (B5) & 61.5 & 11.5 & 13.5 & 7.7 & 5.8 \\
\hline $\begin{array}{l}\text { Symptoms of avoidance and } \\
\text { emotional blunting }\end{array}$ & & & & & \\
\hline
\end{tabular}




\begin{tabular}{cccccc} 
Continued & & & & & \\
\hline Sentimental avoidance (C1) & 23.1 & 38.5 & 15.4 & 9.6 & 13.5 \\
Social avoidance (C2) & 40.4 & 19.2 & 11.5 & 19.2 & 9.6 \\
Difficulty remembering (C3) & 34.6 & 26.9 & 11.5 & 13.5 & 13.5 \\
Disinterest in activities (C4) & 42.3 & 30.8 & 9.6 & 7.7 & 9.6 \\
$\quad$ Sense of posting (C5) & 44.2 & 3.8 & 15.4 & 19.2 & 17.3 \\
Restriction of affects (C6) & 50.0 & 9.6 & 15.4 & 15.4 & 9.6 \\
Symptoms of over-activation & & & & & \\
Sleep interrupted (D1) & 26.9 & 32.7 & 21.2 & 9.6 & 9.6 \\
Irritability or tantrum (D2) & 59.6 & 13.5 & 5.8 & 11.5 & 9.6 \\
Difficulties of concentration (D3) & 25.0 & 40.4 & 15.4 & 5.8 & 13.5 \\
Exaggerated startle reaction (D5) & 46.2 & 13.5 & 11.5 & 11.5 & 17.3 \\
Associated symptoms & & & & & \\
Guilt & 13.5 & 3.8 & 30.8 & 30.8 & 21.2 \\
Regression & 63.5 & 13.5 & 7.7 & 9.6 & 5.8 \\
\hline
\end{tabular}

Items A to D are included in the DSM-IV criteria (309.81 Post-Traumatic Stress Disorder, American Psychiatric Association, 1994).

By combining the percentages of choice and choice almost every day, the results of the CPTS-RI questionnaire showed that 26 students (50\%) suffered from repetitive and pervasive memories of the event as having images, thoughts and perceptions that have resurfaced spontaneously, unintentionally and without anything triggering them (criterion B1).

The students also presented $52 \%$ for guilt because they felt guilty for not doing something they would have liked to do such as helping someone, etc., or doing something they would not have liked make.

While 36.5\% (criterion C5) and 28.8\% (criterion C2) presented respectively the feeling of detachment (having the impression of being detached or foreign to others and that no one understands what has arrived) and social avoidance (try to avoid certain activities, situations or people who recall the traumatic event).

The calculation of the students' CPTS-RI scores revealed that 41 (78.85\%) participants had PTSD with a severity level between low and severe, while 11 students (21.15\%) did not demonstrate an ESPT and no student had a very severe PTSD. Table 4 shows the severity level of the post traumatic stress disorder given by the scores of CPTS-RI.

Comparing students with ESPT and students without PTSD, we found:

Students with PTSD had more difficulty remembering things they learned at school or at home (because they thought about the event) than students without $\operatorname{PTSD}(t=3.336$ and $p=0.002)$ and these students with ESPT were less attentive and focused than students without PTSD $(\mathrm{t}=2.660$ and $\mathrm{p}=0.010)$.

Students with ESPT had less fun at school than students without PTSD $(\mathrm{t}=$ 2.398 and $\mathrm{p}=0.020$ ). 
Table 4. The Severity Level of Post Traumatic Stress Disorder (PTSD) by CPTS-RI score.

\begin{tabular}{ccc}
\hline & Effective & Percentage (\%) \\
\hline Without PTSD & 11 & 21.15 \\
Low PTSD & 12 & 23.08 \\
Moderate PTSD & 15 & 28.85 \\
Severe PTSD & 14 & 26.92 \\
Very severe PTSD & 0 & 0 \\
\hline
\end{tabular}

Without PTSD < 12; 12 - 24: Low PTSD; 25 - 39: Moderate PTSD; 40 - 59: Severe PTSD; Very severe PTSD $>60$.

Students with PTSD had the most recent event date than students without $\operatorname{PTSD}(\mathrm{t}=-3.251$ and $\mathrm{p}=0.002)$.

Students with PTSD were more depressed than students without PTSD $(\mathrm{t}=$ 4.121 and $\mathrm{p}=0.000)$ and those students with PTSD were more anxious than students without PTSD $(t=3.173$ and $p=0.003)$. Unfortunately, the majority of students $(90.4 \%)$ reported that they had poor school results.

A correlation was found between the following variables.

The higher the age, the higher the alcohol frequency $(r=0.319$ and $p=0.021)$, the anxiety $(\mathrm{r}=0.335$ and $\mathrm{p}=0.015)$ and the poor school results $(\mathrm{r}=0.318$ and $\mathrm{p}$ $=0.021)$ increased.

As parental income declined, student anxiety increased $(\mathrm{r}=-0.280$ and $\mathrm{p}=$ 0.044).

The better the school results, the higher the incidence of tobacco $(r=-0.319$ and $\mathrm{p}=0.021$ ).

The higher the frequency of smoking $(r=0.446$ and $p=0.001)$, the frequency of alcohol $(r=0.613$ and $p=0.000)$ and anxiety $(r=0.274$ and $p=0.049)$, the higher the frequency of drugs illicit has increased.

As the event date decreased, the level of PTSD $(r=-0.419$ and $\mathrm{p}=0.002)$ and depression ( $r=-0.331$ and $\mathrm{p}=0.017)$ increased.

The higher the level of PTSD, the worse the academic results $(r=0.524$ and $p$ $=0.000$ ).

The more the student does not play at school $(r=0.475$ and $p=0.000)$, does not do his homework $(\mathrm{r}=0.334$ and $\mathrm{p}=0.016)$ and his desire to commit suicide $(\mathrm{r}=0.528$ and $\mathrm{p}=0.000)$ increased, the level of depression increased.

There was a correlation between the CPTS-RI score and the STAIY and CDI scores $(\mathrm{r}=0.555$ and $\mathrm{p}=0.000)$ and $(\mathrm{r}=0.313$ and $\mathrm{p}=0.024)$ respectively.

Comorbids disorders anxiety and depression are the most common pathologies associated with PTSD and they are assessed by the STAIY and CDI scales that demonstrated that $44(84.62 \%)$ students are anxious and $8(15.38 \%)$ are anxiety-free. While, 43 students (82.7\%) have depression and 9 (17.3\%) students do not have a depression. Table 5 demonstrates the different levels of anxiety and depression in students. 
Table 5. Level of Anxiety (STAIY) and Level of Depression (CDI) according to the scores.

\begin{tabular}{ccc}
\hline & Effective & Percentage (\%) \\
\hline Level of anxiety & 8 & 15.4 \\
Without anxiety $(<35)$ & 8 & 15.4 \\
Low anxiety $(35-45)$ & 26 & 50.0 \\
Moderate anxiety $(46-55)$ & 8 & 15.4 \\
High anxiety $(56-65)$ & 2 & 3.8 \\
Very high anxiety $(>66)$ & & \\
Level of depression & 9 & 17.3 \\
Not depressed $(<15)$ & 43 & 82.7 \\
Depressive $(>$ or equal 15$)$ & & \\
\hline
\end{tabular}

The majority of students with PTSD are anxious, which involves a combination of behaviors such as avoidance, hesitation, nervousness, worry, uncertainty, withdrawal, ritualized actions and the emotional component of fear. There is a correlation between the STAIY score and the CDI score, the higher the level of anxiety, the higher the level of depression $(r=0.434$ and $p=0.001)$.

\section{Discussion}

The aim of our study was the evaluation of the post-traumatic stress disorder ESPT among students in detention at the center of reform and discipline of the prefecture of Salé in Morocco. The age of the participants is from 13 to 17 years, our main questionnaire the CPTS-RI is interested in the age group of 6ans to 16 ans but according to the scientific literature, one can go up to 17 ans [7] [8] and also the interest of the percentage of this age which is $44.2 \%$. The majority of PTSD studies generally address an adult population [9] [10] [11] [12]. While work in children and adolescents are few: PubMed referenced 13,420 articles on PTSD in adults, against 4830 for children. In recent years, terrorist attacks, sexual assault, abuse and other traumas in childhood and adolescence have been the subject of further research, and studies to this end are in progress increase. On the other hand, there is little literature on young people in prison for this age group.

In our study, we note that the majority of students develop a post-traumatic stress disorder, with different levels of severity, after a traumatic event or during the traumatic event concerning detention. There are $78.85 \%$ of students in custody with PTSD (23\% PTSD low and 55.77\% PTSD moderate and severe), which gives a high rate of PTSD is this is due to this specific population of students who are still in detention, their young age and also the place where studies were conducted (according to a study by Chossegros et al., 2011, Ma et al. [13] [14], young people in high-income countries PTSD rate lower than those who live in low- and middle-income countries such as developing countries), this is why 
they are more likely to develop PTSD. Following traumatic exposure, the percentage of children developing PTSD remains high among adults, ranging from $25 \%$ to $50 \%$, depending on the age and type of trauma experienced [15] [16] [17] [18]. For incarcerated youth, they have a high prevalence of post-traumatic stress disorder in the literature compared to other situations. According to Vanderzee [19], $60 \%-70 \%$ of incarcerated youth exhibit ESPT versus 7 to $12 \%$ of non-incarcerated youth.

According to a longitudinal study by Becker, Kerig, Lim Ezechukwu [20], conducted on a large sample $(n=587)$, indicates that the majority of incarcerated youth (the juvenile delinquency) experienced a traumatic event and nearly $50 \%$ presented with PTSD, as another study found with a population of 64 adolescents recruited from a detention center, Japanese juvenile. Studies by Steiner $\mathrm{H}$, Garcia IG, Matthews Z [21], show that the prevalence of PTSD is between $32 \%$ and $60 \%$ among incarcerated adolescents and another study conducted by themselves, they have found a rate of $51.7 \%$ of PTSD among incarcerated youth of California USA. In addition, a study conducted on a sample of 225 young people recruited in a juvenile detention center in the United States, these young prisoners have levels high levels of post traumatic stress symptoms. Incarcerated adolescents are at higher risk of developing PTSD [22] [23].

According to some studies, there is a higher prevalence of youth with post-traumatic stress disorder in custody ( $10 \%$ more than in the general population). Scientific evidence from Canada and other countries around the world demonstrate unequivocally that even short-term detention leads to high levels of post-traumatic stress symptoms in young people, while long-term detention tends to exacerbate these symptoms. Consequently, the various epidemiological studies carried out show certain heterogeneity in the risk of developing PTSD, this variability appears to be due to the type of trauma experienced and other risk factors and the prevalence of PTSD due to trauma is much higher among incarcerated youth.

In all these aspects and more, detention is described as highly harmful to the young person. The deprivation of liberty, as short as it is, will have a very strong impact on the rest of the young person's journey, with social, emotional, psychological or academic sequels [24].

As for smoking, alcohol and illicit drugs, $92.3 \%$ of tobacco, $34.6 \%$ of alcohol and $63.5 \%$ of illicit drugs were found which implies a high consumption of its substances. According to research by Haller et al. [25], conducted in a detention center in Switzerland, "substance abuse is common" in detention, with tobacco being the most consumed with $64.4 \%$ of young prisoners, followed by cannabis (31.3\%), alcohol (26.2\%) and finally other drugs (4.6\%). Overall, the research that has been done gives us a range of $20 \%$ to $50 \%$ of young people with substance abuse [26]. The more the individual has experienced traumatic events, the more likely he will be to smoke, to develop an excessive consumption of alcohol, but also to have a low level of education, as well as an implication in the violence 
[27].

In prison, there is excessive consumption of alcohol or drugs [28] and in another research, an abuse of psychoactive substances [29], so the consumption excessive alcohol or drug use, may associate with PTSD.

In an enclosed and held environment where students are socially lonely and emotionally lonely, they compensate for this lack by meeting with a peer group deviant who will push him to deviance, see delinquency, which leads to a decrease in envy for schooling because of also poor schooling conditions.

In our study, we found $90.4 \%$ of students who dropped school grades, $59.6 \%$ who did not play at school, $61.5 \%$ did not remember what they learned at school and $65.4 \%$ show difficulties in concentration. As the majority of students $82.8 \%$ prove guilt for their unfavorable situation. According to several studies, performance and academic performance are declining when they were normal or good before their detention; imprisonment for young adolescents has a very negative effect on continuity and school life [30] [31] [32] [33].

As well as, other research confirms the negative effect of social and school detention [34] [35]. In our study, high levels of depression (82.7\%) and anxiety (84.62\%) were found for students in detention. In the literature, high levels of anxiety and depression are found in incarcerated adolescents [23] [26] [36] [37]. Most research [38] [39], clearly shows that deprivation of liberty is extremely dangerous for any individual, with an increased risk of depression.

In a study that was developed to define the prevalence of anxiety, depression and post-traumatic stress [40], of 53 Iraqi asylum seekers Denmark. Of all participants, $94 \%$ described symptoms of anxiety, $100 \%$ had symptoms of depression, and $77 \%$ reported symptoms of PTSD. In the United Kingdom, after an average of about 30 days' imprisonment, $76 \%$ of detained asylum seekers were clinically depressed compared to $26 \%$ of comparison sample of non-detained asylum seekers [41]. In the United States, after about 5 months in detention, $86 \%$ of asylum seekers showed clinical levels of depression, $77 \%$ anxiety and 50\% post-traumatic stress disorders [42].

Research in the global literature shows high levels of depression and anxiety among adolescents in custody [43] [44] [45], as well as other work shows the same [46] [47] [48] [49]. Scientific evidence from Canada and other countries around the world demonstrate unequivocally that even short-term detention leads to high levels of depression. Compared with adults, young people are more vulnerable to anxiety and depression [50].

\section{Conclusions}

It is noted that the exposure of a traumatic event can develop in the teenager post traumatic stress disorder, especially for this specific category of students who are in detention. While detainees are very little or not at all prepared for release, and as many experts have pointed out, most of them are unprepared for entry into detention and the life that awaits them [51] [52]. Prison doctors and 
psychologists agree that imprisonment corresponds to an undeniable psychic trauma, by the sudden rupture of the social bond that it entails. PTSD is often associated with other disorders that present the comorbid disorders anxiety and depression in this study. These post-traumatic stress disorders, anxiety and depression have a direct and negative about the school life of students, given the poor results and school disappointment. Lead us to think that prison remains a place of suffering and destabilization. Prison is above all a place that characterizes both the mark of a break with the so-called "normal" world and a space conducive to feeling of exclusion. The desocializing and psychologically destructuring effects are more than proven.

There are the practical implications to deal with this post traumatic stress disorder, which means to treat PTSD in these adolescents in detention and generally used and recommended treatments are TCC or also called CBT (cognitive-behavioral therapies; the TCC is one of the most effective psychotherapeutic treatments) and the drug therapy (the most used drugs are anti-depressants) by the intervention of a professional. There are also other treatments that are EMDR (Eye Movement Desensitization and Reprocessing (of information)), psychoeducation and social and family support.

\section{Conflicts of Interest}

None.

\section{References}

[1] Dyregrov, A. and Yule, W. (2006) A Review of PTSD in Children. Child and Adolescent Mental Health, 11, 176-184. https://doi.org/10.1111/j.1475-3588.2005.00384.x

[2] Pelcovitz, D. and Kaplan, S. (1996) Post-Traumatic Stress Disorder in Children and Adolescents. Child and Adolescent Psychiatric Clinics of North America, 5, 449-469. https://doi.org/10.1016/S1056-4993(18)30375-4

[3] Deering, C.G. (2000) A Cognitive Developmental Approach to Understanding How Children Cope with Disasters. Journal of Child and Adolescent Psychiatric Nursing, 13, 7-16. https://doi.org/10.1111/j.1744-6171.2000.tb00070.x

[4] American Psychiatric Association (1996) DSM-IV, Manuel diagnostique et statistique des troubles mentaux. Traduction Française, Masson, Paris.

[5] Fernandez, L., Marielle, A., et al. (2005) Démarches épidémiologiques après une catastrophe. Module VI, Outils psychométriques.

[6] Spielberger, C.D., Gorsuch, R.L., Lushene, R., Vagg, P.R. and Jacobs, G.A. (1983) Manual for the State-Trait Anxiety Inventory. Consulting Psychologists Press, Palo Alto, CA.

[7] Dogan, A. (2010) Adolescents' Posttraumatic Stress Reactions and Behavior Problems Following Marmara Earthquake. European Journal of Psychotraumatology, 2, 1.

[8] Gindt, M. (2014) Perspectives développementales des marqueurs cognitifs du décours temporel des symptômes ESPT. Thèse de doctorat, Université Nice Sophia Antipolis, Nice.

[9] Golier, J.A., Yehuda, R., Lupien, S.J. and Harvey, P.D. (2003) Memory for Trau- 
ma-Related Information in Holocaust Survivors with TSPT. Psychiatry Research, 121, 133-143. https://doi.org/10.1016/S0925-4927(03)00120-3

[10] Nixon, R.D., Nishith, P. and Resick, P.A. (2004) The Accumulative Effect of Trauma Exposure on Short-Term and Delayed Verbal Memory in a Treatment-Seeking Sample of Female Rape Victims. Journal of Traumatic Stress, 17, 31-35. https://doi.org/10.1023/B:JOTS.0000014673.02925.db

[11] Pederson, C.L., Maurer, S.H., Kaminski, P.L., Zander, K.A., Peters, C.M., Stokes Crowe, L.A. and Osborn, R.E. (2004) Hippocampal Volume and Memory Performance in a Community-Based Sample of Women with Posttraumatic Stress Disorder Secondary to Child Abuse. Journal of Traumatic Stress, 17, 37-40. https://doi.org/10.1023/B:JOTS.0000014674.84517.46

[12] Rohleder, N., Joksimovic, L., Wolf, J.M. and Kirschbaum, C. (2004) Hypocortisolism and Increased Glucocorticoid Sensitivity of Pro-Inflammatory Cytokine Production in Bosnian War Refugees with Post-Traumatic Stress Disorder. Biological Psychiatry, 55, 745-751. https://doi.org/10.1016/j.biopsych.2003.11.018

[13] Chossegros, L., Hours, M., Charnay, P., Bernard, M., Fort, E., Boisson, D., Sancho, P.-O., Yao, S.N. and Laumon, B. (2011) Predictive Factors of Chronic Post-Traumatic Stress Disorder 6 Months after a Road Traffic Accident. Accident Analysis \& Prevention, 43, 471-477. https://doi.org/10.1016/j.aap.2010.10.004

[14] Ma, X., Liu, X., Hu, X., Qiu, C., Wang, Y., Huang, Y. and Li, T. (2011) Risk Indicators for Posttraumatic Stress Disorder in Adolescents exposed to the 5.12 Wenchuan Earthquake in China. Psychiatry Research, 189, 385-391. https://doi.org/10.1016/j.psychres.2010.12.016

[15] Berkowitz, S., Stover, C. and Marans, S. (2010) The Child and Family Traumatic Stress Intervention: Secondary Prevention for Youth at Risk of Developing PTSD. Journal of Child Psychology and Psychiatry, and Allied Disciplines, 52, 676-685. https://doi.org/10.1111/j.1469-7610.2010.02321.x

[16] Huemer, J., Erhart, F. and Steiner, H. (2010) Posttraumatic Stress Disorder in Children and Adolescents: A Review of Psychopharmacological Treatment. Child Psychiatry Human Development, 41, 624-640. https://doi.org/10.1007/s10578-010-0192-3

[17] Kearney, C., Wechsler, A., Kaur, H. and Lemos-Miller, A. (2010) Posttraumatic Stress Disorder in Maltreated Youth: A Review of Contemporary Research and Thought. Clinical Child Family Psychology Review, 13, 46-76. https://doi.org/10.1007/s10567-009-0061-4

[18] Ularntinon, S., Piyasil, V., Ketumarn, P., Sitdhiraksa, N., Pityaratstian, N., Lerthattasilp, T. and Pimratana, W. (2008) Assessment of Psychopathological Consequences in Children at 3 Years after Tsunami Disaster. Journal of the Medical Association of Thailand, 91, S69-S75.

[19] Vanderzee, K.L. (2011) The Role of Avoidance and Numbing among Detained Youth: A Mediation Model. Thèse de doctorat présentée devant le Département de psychologie de l'Univsersité de Miami, Oxford.

[20] Becker, S.P., Kerig, P.K., Lim, J.Y. and Ezechukwu, R.N. (2012) Predictors of Recidivism among Delinquent Youth: Interrelations among Ethnicity, Gender, Age, Mental Health Problems, and Posttraumatic Stress. Journal of Child and Adolescent Trauma, 5, 145-160. https://doi.org/10.1080/19361521.2012.671798

[21] Steiner, H., Garcia, I.G. and Mathews, Z. (1997) Posttraumatic Stress Disorder in Incarcerated Juvenile Delinquents. Journal of the American Academy of Child and Adolescent Psychiatry, 36, 357-365. 
https://doi.org/10.1097/00004583-199703000-00014

[22] Foy, D., Madvig, B., Pynoos, R. and Camilleri, A. (1996) Etiologic Factors in the Development of Posttraumatic Stress Disorder in Children and Adolescents. Posttraumatic Stress Disorder, 34, 133-145. https://doi.org/10.1016/0022-4405(96)00003-9

[23] Falissard, B., Loze, J.Y., Gasquet, I., Duburc, A., de Beaurepaire, C., Fagnani, F. and Rouillon, F. (2006) Prevalence of Mental Disorders in French Prisons for Men. BMC Psychiatry, 6, Article No. 33. https://doi.org/10.1186/1471-244X-6-33

[24] Marie, F. (2017) Prise en charge des jeunes privés de liberté Enjeux et questionnements dans le contexte suisse romand, Mémoire No CIDE 2017/MIDE 15-17/08.

[25] Haller, D., Sebo, P., Cerutti, B., Bertrand, D., Eytan, A., Niveau, G., Wolff, H. and Narring, F. (2010) Primary Care Services Provided to Adolescents in Detention: A Cross Sectional Study Using ICPC-2. Acta Paediatrica, 99, 1060-1064. https://doi.org/10.1111/j.1651-2227.2010.01716.x

[26] Teplin, L., Abram, K.M., McClelland, G.M., Mericle, A.A., Dulcan, M.K. and Washburn, J.J. (2006) Psychiatric Disorders of Youth in Detention. https://doi.org/10.1037/e511002006-001

[27] Baglivio, M., Epps, N., Swartz, K., Sayedul Huq, M., Sheer, A. and Hardt, N. (2014) The Prevalence of Adverse Childhood Experiences (ACE) in the Lives of Juvenile Offenders. OJJDP Journal of Juvenile Justice, 3, 1-23.

[28] Wallace, C., Mullen, P., Burgess, P., Palmer, S., Ruschena, D. and Browne, C. (1998) Serious Criminal Offending and Mental Disorder: Case Linkage Study. British Journal of Psychiatry, 172, 477-484. https://doi.org/10.1192/bjp.172.6.477

[29] Vicky, Y.-M. (2015) La trajectoire de changement d'hommes ayant vécu des événements potentiellement traumatogènes. Université de Montréal École de Criminologie Faculté des arts et des sciences, 19.

[30] Coslin, P. (2003) Les conduites à risque à l'adolescence. Armand Colin, Paris.

[31] Coslin, P. (2007) La socialisation de l'adolescent. Armand Colin, Paris.

[32] Cornell, D. and Heilbrun, A. (2016) School-Based Risk Factors, Bullying, and Threat Assessment. In: Heilbrun, D.K., DeMatteo, D. and Goldstein, N., Eds., $A P A$ Handbook of Psychology and Juvenile Justice, American Psychological Association, Washington DC. https://doi.org/10.1037/14643-011

[33] Esterle-Hedibel, M. (2006) Absentéisme, déscolarisation, décrochage scolaire, les apports des recherches récentes. Déviance et Société, 30, 41-65. https://doi.org/10.3917/ds.301.0041

[34] Abdellaoui, S. and Blatier, C. (2006) les jeunes en détention, Mission de Recherche Droit et Justice (Groupement d'Intérêt Public).

[35] Cleveland, J., Rousseau, C. and Kronick, R. (2012) Les effets néfastes de la détention et de la séparation familiale sur la santé mentale des demandeurs d'asile dans le contexte du projet de loi C-31, 2012 Mémoire soumis au Comité parlementaire permanent de la citoyenneté et de l'immigration sur le projet de loi C-31, Loi visant à protéger le système d'immigration canadien.

[36] Chambers, J.A., Power, K.G., Loucks, N. and Swanson, V. (2000) Psychometric Properties of the Parental Bonding Instrument and Its Association with Psychological Distress in a Group of Incarcerated Young Offenders in Scotland. Social Psychiatry and Psychiatric Epidemiology, 35, 318-325.

https://doi.org/10.1007/s001270050245 
[37] Ducrocq, F., Vaiva, G., Cottencin, O., et al. (2001) Etat de stress post-traumatique, dépression post-traumatique et épisode dépressif majeur: La littérature. Encéphale, 27, 159-168.

[38] Moret, A. (2009) La peine privative de liberté pour mineurs en droit pénal suisse: Faut-il construire de nouvelles prisons pour mineurs? Revue internationale de criminologie et de police technique et scientifique, 3, 185-206.

[39] Jaffé, P., Sulima, S. and Hirschi, C. (2016) Le contexte psychologique des enfants privés de liberté. https://doi.org/10.3917/jdj.351.0073

[40] Schwarz-Nielsen, K.H. and Elklitt, A. (2009) An Evaluation of the Mental Status of Rejected Asylum Seeker in Two Danish Asylum Centers. Torture, 19, 51-59.

[41] Robjant, K., Robbins, I. and Senior, V. (2009) Psychological Distress amongst Immigration Detainees: A Cross-Sectional Questionnaire Study. British Journal of Clinical Psychology, 48, 275-286. https://doi.org/10.1348/014466508X397007

[42] Keller, A.S., Rosenfeld, B., Trinh-Shevrin, C., Meserve, C., Sachs, E., Leviss, J.A., et al. (2003) Mental Health of Detained Asylum Seekers. The Lancet, 362, 1721-1723. https://doi.org/10.1016/S0140-6736(03)14846-5

[43] Zinger, I. and Wichmann, C. (1999) Les répercussions psychologiques d'une période de 60 jours en isolement préventif. http://www.csc-scc.gc.ca/recherche/092/r85_f.pdf

[44] Harding, T. and Zimmerman, E. (1989) Psychiatric Symptoms, Cognitive Stress and Vulnerability Factors. A Study in a Remand Prison. British Journal of Psychiatry, 155, 36-43. https://doi.org/10.1192/bjp.155.1.36

[45] Brent, D.A., Perper, J.A., Moritz, G., et al. (1995) Traumatic Events and Posttraumatic Stress Disorder in Peers of Adolescent Suicide Victims. Journal of the American Academy of Child and Adolescent Psychiatry, 34, 209-215. https://doi.org/10.1097/00004583-199502000-00016

[46] Yehuda, R. and McFarlane, A.C. (1995) Conflict between Current Knowledge about Posttraumatic Stress Disorder and Its Original Conceptual Basis. American Journal of Psychiatry, 152, 1705-1713. https://doi.org/10.1176/ajp.152.12.1705

[47] Domalanta, D.D., Risser, W.L., Roberts, R.E., et al. (2003) Prevalence of Depression and Other Psychiatric Disorders among Incarcerated Youths. Journal of the American Academy of Child and Adolescent Psychiatry, 42, 477-484. https://doi.org/10.1097/01.CHI.0000046819.95464.0B

[48] Ulzen, T. (2003) Post Traumatic Stress Disorder in Incarcerated Adolescents. The Canadian Child and Adolescent Psychiatry Review, 12, 113-116.

[49] Abram, K., Washburn, J.J., Teplin, L., Emanuel, K., Romero, E.G. and McClelland, G.M. (2007) Posttraumatic Stress Disorder and Comorbidity in Detained Youth. Psychiatric Services, 58, 1311-1316.

[50] Kerig, P.K. and Becker, S.P. (2010) Chapter 2: From Internalizing to Externalizing: Processes Linking PTSD to Juvenile Delinquency. In: Egan, S.J., Eds., Post-Traumatic Stress Disorder, 1-46.

[51] Mazerol, M.T. (1985) Les effets psychologiques de la détention. Ministère de la Justice, Paris, 173-190.

[52] Escobart and Molina, A. (1989) L'enfermement. Klincksieck, Paris. 


\section{Abbreviations}

PTSD: Post-traumatic stress disorder

DSM-IV: Diagnostic and statistical manual for mental disorders fourth version CPTS-RI: Children post traumatic stress reaction index

STAIY: State trait inventory anxiety form Y

CDI: Children depression inventory

ICD: International classification of diseases 